\title{
Epidemiological and Clinical Profile of Male Hypofertility in Consultation at the Urology-Andrology of Yalgado Ouedraogo Teaching Hospital (Burkina Faso)
}

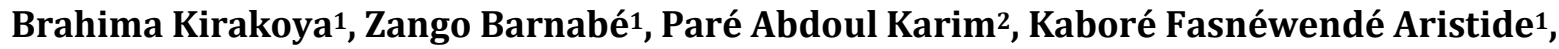 \\ Yaméogo Clotaire ${ }^{1}$, Nikièma Amélie ${ }^{1}$ \\ ${ }^{1}$ Department of Urology, Yalgado Ouedraogo Teaching Hospital of Ouagadougou, Ouagadougou, Burkina Faso \\ ${ }^{2}$ Department of Urology, Hubert Koutoucou Maga Teaching Hospital of Cotonou, Cotonou, Benin \\ Email: " boupare@yahoo.fr
}

Received 21 October 2014; revised 21 November 2014; accepted 23 December 2014

Copyright (C) 2015 by authors and Scientific Research Publishing Inc.

This work is licensed under the Creative Commons Attribution International License (CC BY).

http://creativecommons.org/licenses/by/4.0/

(c) (i) Open Access

\begin{abstract}
Objective: To determine the epidemiological and clinical characteristics of male hypofertility attending at urology for paternity desire. Materials and methods: Cross-sectional study conducted from January $1^{\text {st }}$ to December 312012 at urology department of teaching hospital Yalgado Ouedraogo. We collated men attending for hypofertility. Only subjects living regularly with their partner were retained. Results: The study concerned 95 men. The average age was 36.9 years (range: 23 years and 53 years) and 28.6 years for their wives (range: 19 years and 40 years). Patients resided in urban areas in $\mathbf{9 0 . 5 \%}$ of cases. Gynecologists and general physicians sent respectively $77.9 \%(\mathrm{~N}=$ 74) and $17.9 \%(N=17)$ of cases. The average consultation delay time was 3 years. The average duration of infertility was 5.8 years (Extreme: 1 year and 20 years). Infertility was primary in $68.4 \%$ of cases and secondary in $31.6 \%$ of cases. $24.2 \%$ of patients admitted for history of genitourinary infection. Varicocele was found in $22.1 \%$ of cases. The semen analysis showed that 42 men had azoospermia. The semen culture isolated a germ in $19.1 \%$ of cases. Serum FSH was high in $\mathbf{4 7 . 3 \%}$ of cases. Conclusion: Male hypofertility affected men of all age. Urologists are the last resort of the male hypo fertile, gynecologists constituting the first contact. Azoospermia is a problem commonly encountered in urological consultation.
\end{abstract}

\section{Keywords}

Male Infertility, Azoospermia, Hypofertility

${ }^{*}$ Corresponding author.

How to cite this paper: Kirakoya, B., et al. (2015) Epidemiological and Clinical Profile of Male Hypofertility in Consultation at the Urology-Andrology of Yalgado Ouedraogo Teaching Hospital (Burkina Faso). Advances in Sexual Medicine, 5, 1-6. 


\section{Introduction}

In the world and particularly in Africa, infertility is more than a health problem but a psychosocial problem [1] [2]. Prevalence is very high in sub-Saharan Africa, where one third of the couples would be affected [3]. Males' responsibility for the couple's infertility is in $40 \%-50 \%$ of cases [3] [4]. Substantial progress has been made in the treatment of male infertility in terms of the rapeutic sinetiological research [5]. This contrasts the prevalence of the disease in steadily increasing [6]. In our practice, very few studies have been devoted to male infertility. The aim of this study was to identify clinical, etiological and epidemiological profile of male infertility at the urology department to improve its management.

\section{Patients and Methods}

It was a descriptive cross-sectional study covered over a period of 12 months from $1^{\text {st }}$ January to 31 December 2012. The Urology department of teaching Hospital Yalgado Ouedraogo has provided a framework study. It covered topics consultant male desire of fatherhood. Were included in the study all men who viewed desire for paternity and having regular sexual intercourse with or without contraception, the same joint for at least 12 months and leading a regular life with their partners. Consent was obtained from the patient for publication. All selected subjects had at least two spaced at least three months sperm balance sheets consist of a semen analysis, spermocytogram and a semen culture. Semen was collected in the laboratory after an abstinence of 3 to 5 days. Collection after masturbation was preferred to the interrupted whenever possible coitus. Semen analysis was performed according to the WHO standards. Hormonal balance sheet included serum follicle stimulating hormone (FSH) and testosterone. The variables studied were related to:

-Socio-demographic characteristics,

-Clinical,

-Semen analysis, spermocytogram, FSH, testosterone and ultrasonography.

The variables were analyzed in terms of frequency and average. No statistical analysis had done for comparisons among groups. The study has been performed with the approval of a medical ethics committee.

\section{Results}

During the study period, 3151 patients were admitted at the urology department and 95 male for infertility. The prevalence was $3 \%$. The average age of patients was 36.9 years $(S D=6.8)$ with extremes of 23 years and 53 years. Almost $74 \%$ of patients were less than 41 years (Table 1 ).

The average age of brides was 28.6 years $(\mathrm{SD}=4.9)$ with extremes of 19 years and 40 years. Officials, merchants and farmers accounted respectively $32 \%, 25 \%$ and $15 \%$. Nearly $90.5 \%$ of the patients resided in urban areas. They were monogamous in $96.8 \%(\mathrm{~N}=92)$ of cases and polygamous in $3.2 \%$ of cases. Patients were referred by gynecologists in $77.9 \%(\mathrm{~N}=74)$ of cases and by general physicians in $17.9 \%(\mathrm{~N}=17)$ of cases. Only $4.2 \%(\mathrm{~N}=4)$ of patients were received in consultation by themselves. The average consultation delay was 3 years $(\mathrm{SD}=2.1)$ and ranged from 1 year to 10 years (Figure 1$)$.

The average duration of infertility was 5.8 years $(\mathrm{SD}=3.9)$ and ranged from 1 year to 20 years. The average frequency of sexual intercourse was 2 to 3 times per week in $98.9 \%$ of cases. Infertility was primary in $68.4 \%$ of cases and secondary in $31.6 \%$ of cases. The history of genitourinary infection were noted in $24.2 \%(\mathrm{~N}=23)$. Six patients reported, had contracted bilharzia urogenital childhood. Patient histories were reported in Table 2.

Two cases of obesity were observed with body mass index of $31.1 \mathrm{~kg} / \mathrm{m}^{2}$ and $37.5 \mathrm{~kg} / \mathrm{m}^{2}$. The review found 7 cases $(7.4 \%)$ of acute prostatitis. Clinical and ultrasonography examination of the scrotal contents found 21 cases (22.1\%) of varicocele, 8 cases of cryptorchidism including 3 bilateral, 4 cases of testicular atrophy and 13 cases of testicular hypotrophy. The semen analysis was performed on 94 patients. In one case there was an anejaculation. The Urine culture in post coital period performed twice did not find any sperm.

The spermatic balance of the whole study population was disrupted. The spermatic profile of our sample was reported in Figure 2.

Azoospermia was found in $47.6 \%(\mathrm{~N}=10)$ of subjects with varicocele. The semen culture isolated a germ in 18 cases $(19.1 \%)$. It was the staph in $12.7 \%$ of cases $(\mathrm{N}=12)$, streptococcus in $2.1 \%$ of cases $(\mathrm{N}=2)$ and pseudomonas in $1 \%$ of cases $(\mathrm{N}=1)$. Candida albicans was isolated in 3 cases. In these three cases, the collection of sperm occurred in the laboratory by interrupted coitus. 
Table 1. Distribution of the patients according age group.

\begin{tabular}{ccc}
\hline Age group & Number & Percent (\%) \\
\hline $20-30$ & 15 & 15.8 \\
$31-40$ & 55 & 57.9 \\
$41-50$ & 22 & 23.2 \\
$51-60$ & 3 & 3.1 \\
Total & 95 & 100 \\
\hline
\end{tabular}

Table 2. Distribution of the patients according background.

\begin{tabular}{ccc}
\hline Background & Number \\
Oreillon & 15 \\
Urethritis & 10 \\
Epididymoorchitis & 12 \\
Mumps orchitis & 01 \\
Bilharzia & 06 \\
Inguinal hernia & 04 \\
Hydrocele & 05 \\
Uretroplasty & 01 \\
Scrotal injury & 03 \\
\hline
\end{tabular}

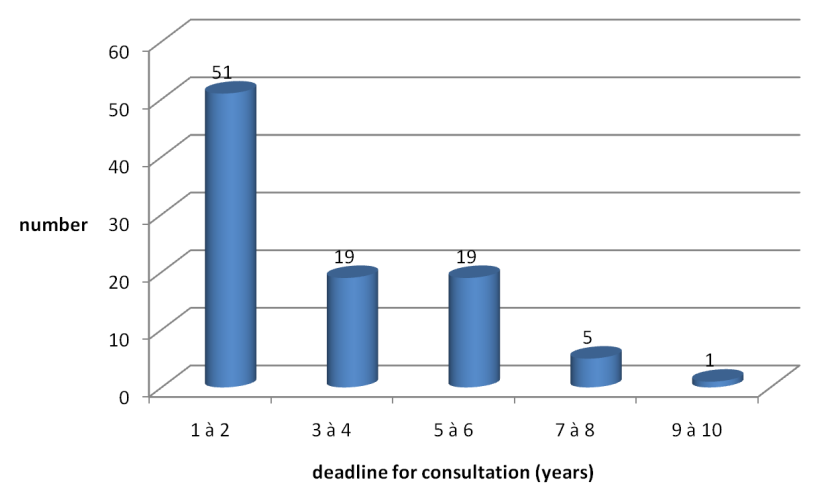

Figure 1. Distribution of the patients according deadline of consultation.

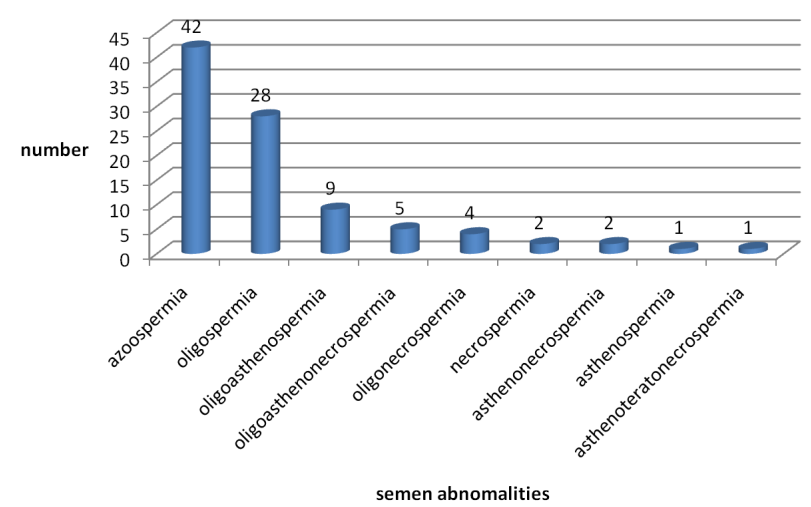

Figure 2. Distribution of the patients according semen abnormalities.

Determination of serum FSH was performed by $57.9 \%(\mathrm{~N}=55)$ patients. The rate was normal in $52.7 \%$ of cases $(\mathrm{N}=29)$ and increased in $47.3 \%$ of cases. The elevation of FSH was found in $40.5 \%(\mathrm{~N}=17)$ of azoospermia. The 
blood level of testosterone was achieved by 45 patients. The testosterone was low in 3 cases and normal in 42 cases.

\section{Discussion}

Compared to other African series, the annual incidence of male infertility in our study was low. Its concerned $3 \%$ of all consultations in the service. It accounted for $8.2 \%$ of all consultations in the series of Bah et al. in Guinea Conakry [7]. This low frequency of the disease in our series does not seem to reflect the actual level of pathology in hospitals let alone society. The route of the infertile couple in southern societies seems more complex [1]. The use of traditional healer and religious circles for prayers first intension is the rule. This attitude is motivated by the level of knowledge on the issue and the socio-cultural aspects of infertility [1] [2] [8].

In hospitals, two medical specialties share the management of male infertility. These are the obstetrics gynecology and urology and rology. Obstetric gynecologist is the specialty at the forefront. Most of our patients (77.9\%) were referred by the gynecologist. Patients referred to the urology consultation for infertility would be those who have deep sperm alterations requiring uro-andrology exploration. Urology seems to be the last resort in the treatment of male infertility in our practice.

Age is known as a determining factor in the fertility of the couple. It is more damaging in the female. The decline in male fertility with age is a well-accepted concept [9]. The reasons given are many involving impairment of sperm parameters to genomic alterations of the sperm with age [10]. Those reasons are amplified by an alteration of sperm parameters recorded in the last two decades [6]. This is a disease in young patients in the African series, 34 in the series of Ahmed et al. in Nigeria [11], 39 in the series of Bah et al. in Guinea Conakry [7] and that of Niang et al. in Senegal [12] and 36.9 years in our series. The primary type of infertility was predominant in most series [7] [11] [12] confirming our observations. In all cases the etiological research is an absolute necessity. Urogenital infections, main providers of obstruction of sperm ducts were found in $24.2 \%$ of patients in the study population. In addition to the obstruction they cause infections lead to a destruction of germ cells [13]. It is irreversible, these cells do not have the capacity to renew itself. Sperm quality can provide guidance on the infectious origin of the alteration; oligospermia, viscosity increase, decreased $\mathrm{pH}$, low concentration of secreted by glands [13] components. Urogenital infections are the main causes of infertility both in men than in women of African environment [4] [11] [14]. It can be active infection or sequelae. Once formed, the results of management of infertility are random. Several pathogens infecting the male urogenital tract have been implicated. Gonorrhea was the most found in the study of Bah et al. [7]. Staphylococcus was the most found in the semen culture in our series as well as in the series of Owolabie et al. [15] in Nigeria. The relationship between schistosomiasis infection and male infertility is a particularity of the African environment. Patil et al. [16] were found in a study autopsy prostate achieved in nearly $58 \%$ and a violation of the seminal vesicles in $50 \%$ of cases. Schistosoma haematobium was the only involved agent. Frequently, the infestation is old since childhood or adolescence. It could have been symptomatic or not, treated or untreated. The actual impact of urogenital schistosomiasis in the occurrence of male infertility remains unclear. Its contributed by them aftermath which were irreversible. We found a history of urogenital schistosomiasis in 6 cases $(6.3 \%)$.

Varicocele was the most observed physical signs (22.1\%). Its involvement in the genesis of male infertility remains controversial. Its management is more so especially in developed countries where the use of medically assisted procreation seems more advantageous in terms of cost and performance [17].

The spermatic balance was disturbed in all patients. Azoospermia was the most anomaly found (44.7\%). The high prevalence of infectious and surgical history, anomalies reported by physical and ultrasound examination are crucial elements of the spermatic balance disturbances. The rates of different sperm abnormalities are variable depending on the series. Owolabi et al. [15] in Nigeria, Lee et al. [18] in Korea and Bah et al. [7] in Guinea Conakry reported respectively $6.2 \%, 10.5 \%$ and $39.3 \%$ of azoospermia. The management of a zoospermia remains a challenge for the urologyst. It is guided by its etiology. Azoospermia were grouped into two categories: obstructive azoospermia and non obstructive azoospermia. Obstructive azoospermia are more common in African environment because of the prevalence of infectious diseases [11] [12] [19]. The high rate of azoospermia associated with anormal FSH levels (59.5\% of azoospermia) in our series argues for an obstructive etiology most likely acquired in our context. In the series of Lee et al. [18] obstructive azoospermia and non-obstructive azoospermia represented respectively $25 \%$ and $71 \%$ of all azoospermia. Azoospermia in our study was associated with elevated FSH levels in $40.5 \%$ of cases moving towards gonadal causes. Testicular biopsy and histology have helped refine the diagnosis. This exploration is exceptional in our practice. This information can't be re- 
duced only to the diagnosis. Significant advances in the field of reproductive biology have been made in recent years especially in the field of genetics [5] reducing the scope of idiopathic infertility. In the series Lee et al. [18], chromosomal abnormalities were the second leading cause of non obstructive azoospermia. In our practice, exploration of male infertility is limited to the clinical examination, the spermatic balance sheet, endocrinology and ultrasound. The cost of examinations especially hormonology same routine is a hindrance to exploration rights. Only $57.9 \%$ of our sample was able to achieve a dosage of FSH.

\section{Conclusion}

The exploration of the male infertility with gradual approach will often determine the obvious causes. Urogenital infections were the most frequent diagnoses found in our environment. A logical management of male infertility should interest man and his partner by the same multidisciplinary team including at least uro-andrologist, gynecologist and reproductive biologist. This could raise the level of health care provision and identify areas of research to better management of male infertility.

\section{References}

[1] Ali, S., Sophie, R., Imam, A.M., Khan, F.I., Ali, S.F., Shaikh, A., et al. (2011) Knowledge, Perceptions and Myths Regarding Infertility among Selected Adult Population in Pakistan: A Cross-Sectional Study. BMC Public Health, 11, 760. http://dx.doi.org/10.1186/1471-2458-11-760

[2] Tabong, P.T. and Adongo, P.B. (2013) Understanding the Social Meaning of Infertility and Childbearing: A Qualitative Study of the Perception of Childbearing and Childlessness in Northern Ghana. PLoS One, 8. http://dx.doi.org/10.1371/journal.pone.0054429

[3] Inhorn, M.C. (2003) Global Infertility and the Globalization of New Reproductive Technologies: Illustrations from Egypt. Social Science \& Medicine, 56, 1837-1851. http://dx.doi.org/10.1016/S0277-9536(02)00208-3

[4] Ikechebelu, J.I., Adinma, J.I., Orie, E.F. and Ikegwuonu, S.O. (2003) High Prevalence of Male Infertility in Southeastern Nigeria. Journal of Obstetrics \& Gynaecology, 23, 657-659. http://dx.doi.org/10.1080/01443610310001604475

[5] Matzuk, M.M. and Lamb, D.J. (2008) The Biology of Infertility: Research Advances and Clinical Challenges. Nature Medicine, 14, 1197-1213. http://dx.doi.org/10.1038/nm.f.1895

[6] Mukhopadhyay, D., Varghese, A.C., Pal, M., Banerjee, S.K., Bhattacharyya, A.K., Sharma, R.K., et al. (2010) Semen Quality and Age-Specific Changes: A Study between Two Decades on 3,729 Male Partners of Couples with Normal Sperm Count and Attending an Andrology Laboratory for Infertility-Related Problems in an Indian City. Fertility and Sterility, 93, 2247-2254. http://dx.doi.org/10.1016/j.fertnstert.2009.01.135

[7] Bah, O., Diallo, A., Diallo, A., Guirassy, S., Bah, I., Barry, M., et al. (2007) Infertilité masculine: Fréquence et aspects étiologiques au service d’Urologie-Andrologie du CHU de Conakry. Andrologie, 17, 241-245. http://dx.doi.org/10.1007/BF03040734

[8] Iliyasu, Z., Galadanci, H.S., Abubakar, I.S., Bashir, F.M., Salihu, H.M. and Aliyu, M.H. (2013) Perception of Infertility and Acceptability of Assisted Reproduction Technology in Northern Nigeria. Nigerian Journal of Medicine, 22, 341-347.

[9] Plas, E., Berger, P., Hermann, M. and Pfluger, H. (2000) Effects of Aging on Male Fertility? Experimental Gerontology, 35, 543-551. http://dx.doi.org/10.1016/S0531-5565(00)00120-0

[10] Belloc, S., Hazout, A., Zini, A., Merviel, P., Cabry, R., Chahine, H., et al. (2014) How to Overcome Male Infertility After 40: Influence of Paternal Age on Fertility. Maturitas, 78, 22-29.

http://dx.doi.org/10.1016/j.maturitas.2014.02.011

[11] Ahmed, A., Bello, A., Mbibu, N.H., Maitama, H.Y. and Kalayi, G.D. (2010) Epidemiological and Aetiological Factors of Male Infertility in Northern Nigeria. Nigerian Journal of Clinical Practice, 13, 205-209.

[12] Niang, L., Ndoye, M., Labou, I., Jalloh, M., Kane, R., Diaw, J.J., et al. (2009) Profil épidémiologique et clinique de l’infertilité masculine à l'hôpital général de Grand-Yoff, Sénégal: A propos de 492 cas. Andrologie, 19, 103-107.

[13] Darcq, C. and Hermabessiere, J. (2006) Etiologie des infertilités secondaires de l’homme. Andrologie, 16, $155-159$. http://dx.doi.org/10.1007/BF03034847

[14] Bachir, B.G. and Jarvi, K. (2014) Infectious, Inflammatory, and Immunologic Conditions Resulting in Male Infertility. Urologic Clinics of North America, 41, 67-81. http://dx.doi.org/10.1016/j.ucl.2013.08.008

[15] Owolabi, A.T., Fasubaa, O.B. and Ogunniyi, S.O. (2013) Semen Quality of Male Partners of Infertile Couples in Ile-Ife, Nigeria. Nigerian Journal of Clinical Practice, 16, 37-40. http://dx.doi.org/10.4103/1119-3077.106729

[16] Patil, P.S. and Elem, B. (1988) Schistosomiasis of the Prostate and the Seminal Vesicles: Observations in Zambia. 
Journal of Tropical Medicine and Hygiene, 91, 245-248.

[17] Kantartzi, P.D., Goulis, Ch.D., Goulis, G.D. and Papadimas, I. (2007) Male Infertility and Varicocele: Myths and Reality. Hippokratia, 11, 99-104.

[18] Lee, H.D., Lee, H.S., Park, S.H., Jo, D.G., Choe, J.H., Lee, J.S. and Seo, J.T. (2012) Causes and Classification of Male Infertility in Korea. Clinical and Experimental Reproductive Medicine, 39, 172-175. http://dx.doi.org/10.5653/cerm.2012.39.4.172

[19] Abarikwu, S.O. (2013) Causes and Risk Factors for Male-Factor Infertility in Nigeria: A Review. African Journal of Reproductive Health, 17, 150-166. 
Scientific Research Publishing (SCIRP) is one of the largest Open Access journal publishers. It is currently publishing more than 200 open access, online, peer-reviewed journals covering a wide range of academic disciplines. SCIRP serves the worldwide academic communities and contributes to the progress and application of science with its publication.

Other selected journals from SCIRP are listed as below. Submit your manuscript to us via either submit@scirp.org or Online Submission Portal.
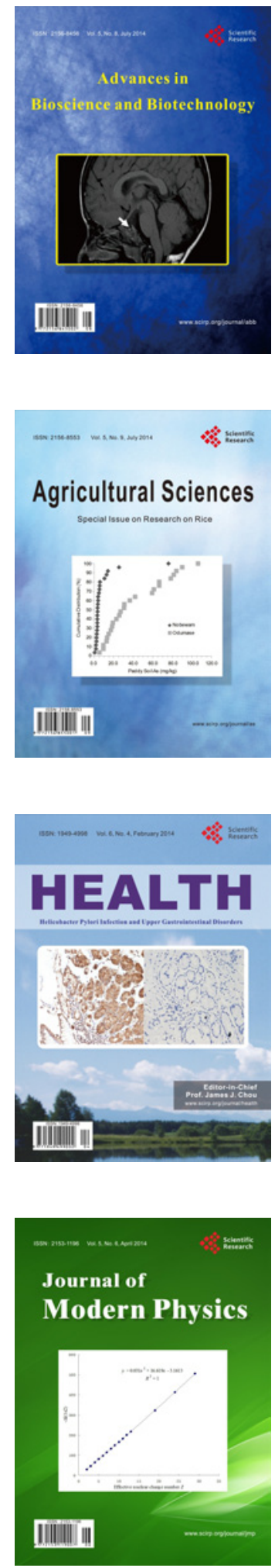
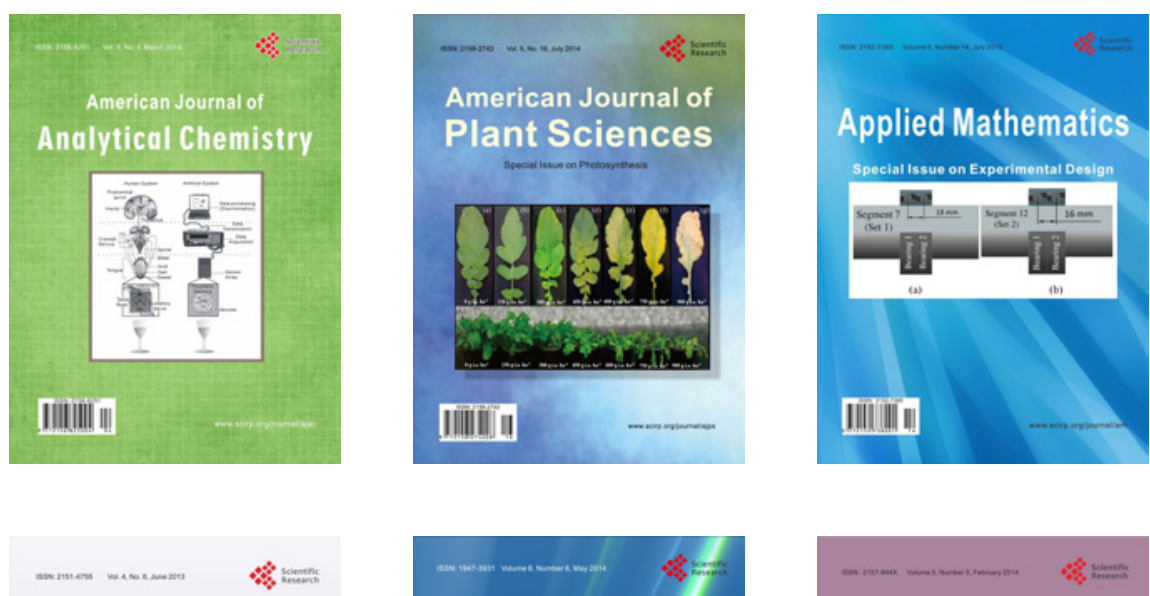

Creative Education
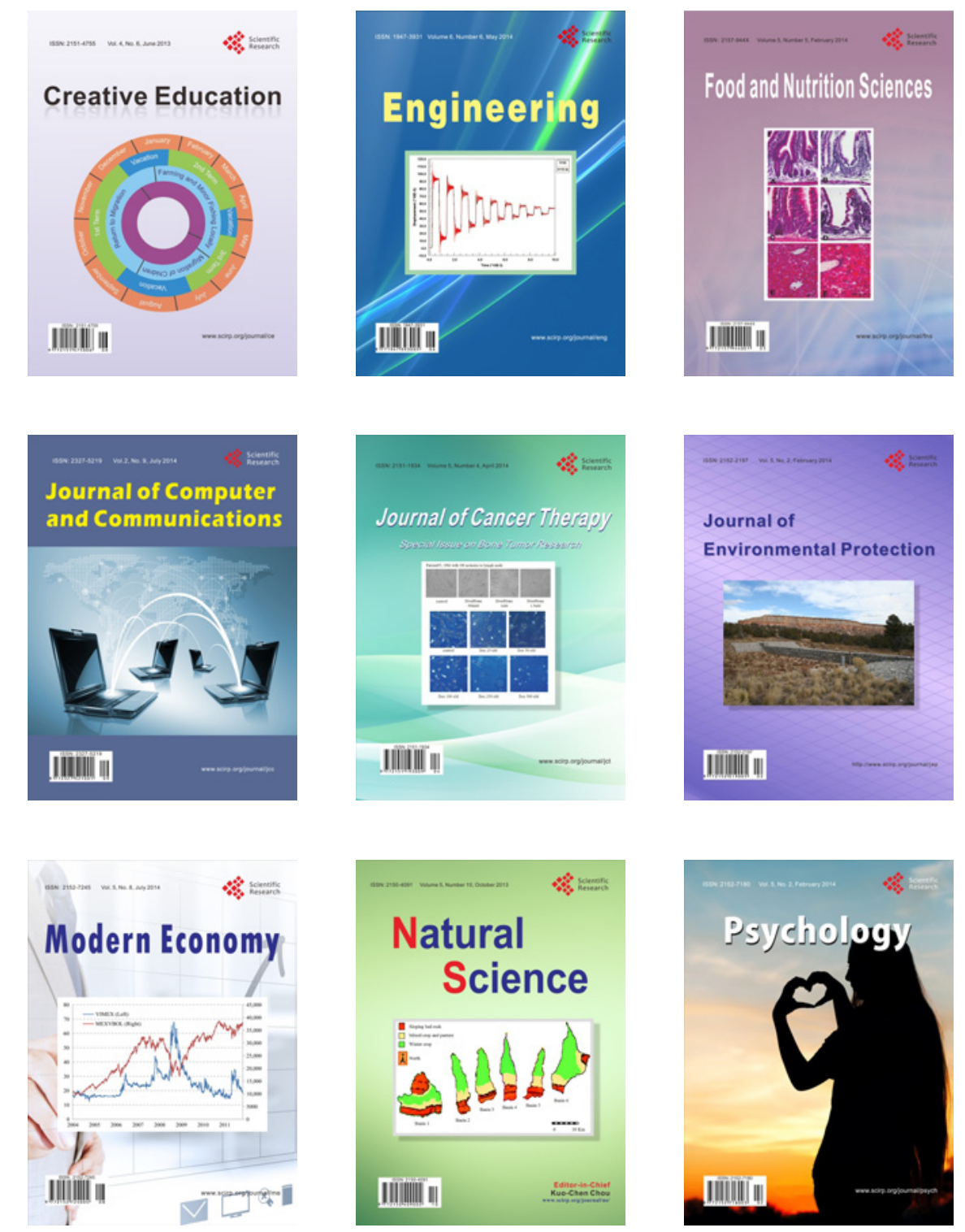